\title{
Validated Method for the Determination of Piroxicam by Capillary Zone Electrophoresis and Its Application to Tablets
}

\author{
Arın Gül Dal, Zeynep Oktayer, and Dilek Doğrukol-Ak \\ Department of Analytical Chemistry, Faculty of Pharmacy, Anadolu University, 26470 Eskişehir, Turkey \\ Correspondence should be addressed to Arın Gül Dal; agdal@anadolu.edu.tr
}

Received 8 July 2014; Revised 21 August 2014; Accepted 21 August 2014; Published 9 September 2014

Academic Editor: Sibel A. Ozkan

Copyright (C) 2014 Arın Gül Dal et al. This is an open access article distributed under the Creative Commons Attribution License, which permits unrestricted use, distribution, and reproduction in any medium, provided the original work is properly cited.

\begin{abstract}
Simple and rapid capillary zone electrophoretic method was developed and validated in this study for the determination of piroxicam in tablets. The separation of piroxicam was conducted in a fused-silica capillary by using $10 \mathrm{mM}$ borate buffer $(\mathrm{pH}$ 9.0) containing $10 \%(\mathrm{v} / \mathrm{v})$ methanol as background electrolyte. The optimum conditions determined were $25 \mathrm{kV}$ for separation voltage and $1 \mathrm{~s}$ for injection time. Analysis was carried out with UV detection at $204 \mathrm{~nm}$. Naproxen sodium was used as an internal standard. The method was linear over the range of $0.23-28.79 \mu \mathrm{g} / \mathrm{mL}$. The accuracy and precision were found to be satisfied within the acceptable limits $(<2 \%)$. The LOD and LOQ were found to be 0.07 and $0.19 \mu \mathrm{g} / \mathrm{mL}$, respectively. The method described here was applied to tablet dosage forms and the content of a tablet was found in the limits of USP-24 suggestions. To compare the results of capillary electrophoretic method, UV spectrophotometric method was developed and the difference between two methods was found to be insignificant. The capillary zone electrophoretic method developed in this study is rapid, simple, and suitable for routine analysis of piroxicam in pharmaceutical tablets.
\end{abstract}

\section{Introduction}

Piroxicam (PIR) (4-hydroxy-2-methyl-N-(pyridine-2-yl)$2 \mathrm{H}-1,2$-benzothiazine-3-carboxamide-1,2-dioxide) is a wellknown nonsteroidal anti-inflammatory and analgesic drug, indicated for acute or long-term treatment of inflammation associated with musculoskeletal and joint disorders, such as osteoarthritis, rheumatoid arthritis, and ankylosing spondylitis [1]. The chemical structure is presented in Figure 1.

Nonsteroidal anti-inflammatory drugs (NSAIDs) are the group of analgesics and anti-inflammatory drugs most often used around the world, mainly to treat pain, inflammation, and fever in human. These pharmaceuticals are weak acidic compounds because of their carboxylic groups or ketoenol tautomeric structure with their $\mathrm{pK}$ values between 3 and 7. Most of the NSAIDs are chiral, but they are often administered as racemates [2].

Several analytical methods have been described for the determination of PIR, including spectrophotometry [39], spectrofluorimetry [10-12], thin-layer chromatography (TLC) $[13,14]$, liquid chromatography (LC) $[9,13-23]$, and capillary electrophoresis (CE) [7, 13, 24-27]. CE has emerged as a powerful analytical technique in the analysis of pharmaceutical compounds, such as NSAIDs [1]. The CE methods developed for the determination of PIR in the previous studies were presented without validation except the study of Bartsch et al. [13] which indicated only precision data. Donato et al. [27] reported also only linearity, precision, and accuracy in injectable formulation of PIR and no further validation was shown.

Two capillary electrophoretic methods were reported for pharmaceutical analysis of PIR. One of them was a micellar electrokinetic chromatography (MEKC) method [7] for tablet analysis. There is no information about analysis and migration time for PIR. Linearity range was not very well specified for the determination of PIR; only the quality control (QC) standards compared to pharmaceutical tablets were also presented without validation. Another method reported by Chen and $\mathrm{Wu}$ [24] was a capillary zone electrophoretic (CZE) method for the simultaneous determination of seven drugs such as PIR, sulindac, ketoprofen, indomethacin, nimesulide, ibuprofen, and naproxen. Linearity range was $13.24-$ $165 \mu \mathrm{g} / \mathrm{mL}$ and LOD was $3.31 \mu \mathrm{g} / \mathrm{mL}$ with 13 min of migration 


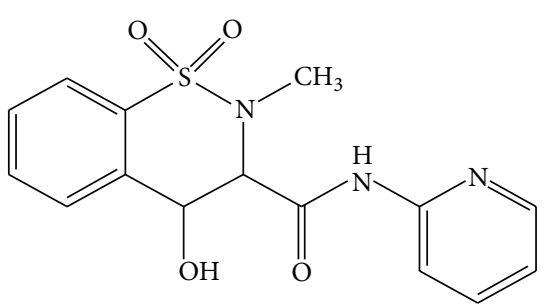

FIgURE 1: The chemical structure of PIR.

time. Bartsch et al. [13] demonstrated PIR photodecomposition using three different concentrations $(40 \mu \mathrm{g} / \mathrm{mL}$, $250 \mu \mathrm{g} / \mathrm{mL}$, and $2 \mathrm{mg} / \mathrm{mL}$ ) by three methods including high performance LC (HPLC), high performance TLC (HPTLC), and CE. The quantification was evaluated only by external calibration without use of internal standard (IS) and only precision data was presented. Migration time for PIR was reported below $3 \mathrm{~min}$. Boone et al. [25] simultaneously separated six acidic drugs such as hydrochlorothiazide, PIR, ibuprofen, phenobarbital, salicylic acid, and chlorothiazide in spiked serum and urine extracts by using CZE, MEKC, and nonaqueous CE (NACE) techniques as well as basic drugs. This study reports only separation of analytes by CZE with $90 \mathrm{mM}$ sodium tetraborate ( $\mathrm{pH} 8.4$ ), by MEKC with $20 \mathrm{mM}$ sodium phosphate and $50 \mathrm{mM}$ SDS (pH 7.5), and by NACE with $20 \mathrm{mM}$ ammonium acetate in methanol/acetonitrile $(9: 1, \mathrm{v} / \mathrm{v})$ containing $1 \%$ acetic acid. PIR $(1 \mu \mathrm{g} / \mathrm{mL})$ eluted up to $4 \mathrm{~min}$ in serum and urine by CZE, up to $12 \mathrm{~min}$ with ibuprofen as unresolved peaks by MEKC and NACE application were not reported for PIR. The results were also presented without validation. Fillet et al. [26] separated 11 NSAIDs including PIR in a background electrolyte solution of $100 \%$ methanol and 13 NSAIDs in a second background electrolyte solution of acetate in methanol and acetonitrile $(70: 30, \mathrm{v} / \mathrm{v})$ by using nonaqueous system showing PIR resolution from other drugs and its migration time appeared up to $8 \mathrm{~min}$ in both systems but the reported study did not cover any method validation or pharmaceutical application.

Therefore there is a need for the determination of PIR in pharmaceutical tablets by CZE with full validation. The aim of this study is to develop a validated, simple, and rapid CZE method for the analysis of PIR in pharmaceutical tablets. The proposed method was linear over wide range of $0.23-28.79 \mu \mathrm{g} / \mathrm{mL}$ and was validated in relation to precision, accuracy, selectivity, and sensitivity (with LOD of $0.07 \mu \mathrm{g} / \mathrm{mL}$ for PIR) in QC standards and tablet matrix. Method accuracy was also confirmed by using UV spectrophotometric method.

\section{Experimental}

2.1. Chemicals. PIR and naproxen sodium (NAP) as IS were purchased from Sigma Chemical Co. (USA). All other chemicals were of analytical grade and were purchased from Merck GmbH Company (Germany). Ultrapure water was purified with a Milli-Q system of Millipore (USA). Commercial PIR tablets (Felden Flash, Pfizer, Turkey) containing $20 \mathrm{mg}$ PIR were obtained from a local pharmacy.
2.2. Apparatus. CE (Thermo Separation Products, Spectra Phoresis 100, USA) was performed with SPD-10A model UV detector (Shimadzu, Japan) and data was processed by CR7A model (Shimadzu, Japan) integrator. Compounds were separated in $75 \mu \mathrm{m}$ i.d. fused-silica tubing of $53.6 \mathrm{~cm}$ effective and $68.2 \mathrm{~cm}$ total length (Agilent Technologies, USA).

Spectrophotometric studies were conducted using UV2401 model spectrophotometer (Shimadzu, Japan). The $\mathrm{pH}$ of the solutions was measured by a model of M-822 pH meter (Electro-mag, Turkey). All solutions were sonicated in a B220 model ultrasonic bath (Branson, USA) before injection.

2.3. Preparation of Solutions. Standard PIR and NAP solutions were prepared in methanol and distilled water, respectively. The final concentration of the IS was always $6.76 \mu \mathrm{g} / \mathrm{mL}$.

Background electrolyte (BGE) consisted of $10 \mathrm{mM}$ borate buffer containing $10 \%$ (v/v) methanol adjusted to $\mathrm{pH} 9.0$.

For UV spectrophotometric experiments $0.36,0.72,1.08$, and $1.44 \mu \mathrm{g} / \mathrm{mL}$ PIR solutions were prepared in methanol and methanol was used as blank. These amounts of PIR were added to unknown tablet solution and absorbance was recorded.

2.4. CZE Procedure. Fused-silica capillary used for the first time was conditioned by flushing with $1.0 \mathrm{M} \mathrm{NaOH}$ for $30 \mathrm{~min}$ followed by $0.1 \mathrm{M} \mathrm{NaOH}$, ultrapure water, and BGE for $10 \mathrm{~min}$, respectively.

Each day, the capillary was washed and conditioned by rinsing for $10 \mathrm{~min}$ with each of $0.1 \mathrm{M} \mathrm{NaOH}$, ultrapure water, and BGE, respectively. The samples were then injected into the fused-silica capillary filled with BGE, by vacuum injection for $1 \mathrm{~s}$. Between each run the capillary was rinsed with $0.1 \mathrm{M}$ $\mathrm{NaOH}$ (2 min), distilled water (2 min), and BGE (2 min). At the end of each working day, it was washed with $0.1 \mathrm{M}$ $\mathrm{NaOH}$ and ultrapure water for $10 \mathrm{~min}$ and left with aspirated air. During analysis the applied potential was $+25 \mathrm{kV}$, under voltage-controlled conditions. Detection was performed at $204 \mathrm{~nm}$.

2.5. Validation Studies. The method was validated according to ICH guidelines for validation of analytical procedures [28].

The precision of the method was determined by the measurement of repeatability (intraday) and intermediate precision (interday). Standard solution of PIR $1.79 \mu \mathrm{g} / \mathrm{mL}$ was injected on three consecutive days, six times in a day.

The linearity of the method was investigated with 8 concentrations in the range of $0.23-28.79 \mu \mathrm{g} / \mathrm{mL}$. Linearity was evaluated by linear regression analysis using the least square regression method. Calibration plots were chosen in this range and six concentrations were injected for three consecutive days.

$0.23 \mu \mathrm{g} / \mathrm{mL}, 1.79 \mu \mathrm{g} / \mathrm{mL}$, and $14.41 \mu \mathrm{g} / \mathrm{mL}$ PIR solutions were used for accuracy studies. The accuracy in matrix was determined by adding PIR onto matrix to give the final concentrations of $0.26,2.56$, and $25.58 \mu \mathrm{g} / \mathrm{mL}$. The matrix was prepared as common tablet excipients such as hydroxypropyl 
methylcellulose $(7 \%)$, lactose monohydrate $(60 \%)$, magnesium stearate (1\%), polyethylene glycol 4000 (5\%), povidone $(5 \%)$, maize starch (5\%), talc (1\%), and titanium dioxide (1\%).

Quantification was accomplished on the basis of PIR to NAP normalized peak area ratios (rPN) [i.e., (peak area of $\mathrm{PIR} /$ migration time of $\mathrm{PIR}) /($ peak area of NAP/migration time of NAP)].

2.6. Tablet Analysis. The method was applied to a PIR tablet as in the pharmacopeial rules [29].

For the application of the method, 10 Felden Flash (each containing $20 \mathrm{mg}$ PIR) tablets were weighed to calculate the average weight of a tablet. 10 tablets were then powdered and the average amount of a tablet was weighed. It was dissolved in $25 \mathrm{~mL}$ methanol and sonicated for $10 \mathrm{~min}$. The solution was centrifuged for $10 \mathrm{~min}$ at $5000 \mathrm{rpm}$. The supernatant was diluted with methanol to the appropriate concentration to measure the amount of PIR.

\section{Results and Discussion}

The $\mathrm{pKa}$ value of PIR is 6.3. Buffer $\mathrm{pH}$ has an influence on the degree of ionization of the molecules, their electrophoretic mobilities, and electroosmotic flow. Therefore, alkaline conditions were considered to be suitable for the determination of PIR according to its molecular structure.

3.1. Optimization of the Method. Experiments were performed to determine the optimum conditions.

Borate buffer was selected for BGE to provide the solubility of PIR. Initially, borate buffer was investigated in the concentration range of $10-25 \mathrm{mM}$ and $15 \mathrm{mM}$ borate provided the optimum results.

Methanol was preferred for the modifier of the BGE because it decreases the mobility of the components in capillary column. It was found out that better migration times and good peak shapes were obtained with the use of $10 \%(\mathrm{v} / \mathrm{v})$ methanol.

The effect of the $\mathrm{pH}$ was tested in the range of 8.5 and 9.5. Well-shaped peaks appeared with the use of $\mathrm{pH}$ 9.0. At this $\mathrm{pH}$, the electroosmotic flow has reached a maximum, fairly constant mobility and PIR is completely ionized, so that its corresponding electrophoretic mobility was not affected by any slight variations in $\mathrm{pH}$. PIR was in an anionic form in the BGE of $\mathrm{pH} 9.0$ and eluted after electroosmosis.

Well-shaped peaks of PIR appeared at $+25 \mathrm{kV}$ and the applied potential was kept at $+25 \mathrm{kV}$. Despite higher voltages which are preferred in CE, voltages higher than $25 \mathrm{kV}$ caused problems such as current generation, poor separation, and resolution between PIR and IS.

An injection time of $1 \mathrm{~s}$ was used because longer duration caused zone broadening.

The optimum conditions determined were as follows: $10 \mathrm{mM}$ borate buffer at $\mathrm{pH} 9.0$, containing $10 \%$ (v/v) methanol for BGE. $+25 \mathrm{kV}$ applied potential and $1 \mathrm{~s}$ of injection time were used as the instrumental parameters. Then NAP was injected as IS, and it appeared in appropriate time and resolution in the electropherogram. Under these analytical and instrumental conditions, the migration times were 8.11 $\pm 0.03 \mathrm{~min}$ for PIR and $8.60 \pm 0.04 \mathrm{~min}$ for $\operatorname{NAP}(n=6)$ as seen in Figure 2(a).

Electroosmotic mobility was calculated as $6.61 \times$ $10^{-6} \mathrm{~cm}^{2} / \mathrm{s} \cdot \mathrm{V}$. Methanol was used as a neutral marker. Electrophoretic mobilities were calculated as $-1.5 \times$ $10^{-4} \mathrm{~cm}^{2} / \mathrm{s} \cdot \mathrm{V}$ for PIR and $-1.66 \times 10^{-4} \mathrm{~cm}^{2} / \mathrm{s} \cdot \mathrm{V}$ for NAP. The electrophoretic mobility for PIR was given as -22.8 $\times 10^{-5} \mathrm{~cm}^{2} / \mathrm{s} \cdot \mathrm{V}$ in only one of the $\mathrm{CE}$ studies which used nonaqueous system [26] and it is not comparable with this study.

3.2. Validation of the Method. The precision of the method was examined as individual days (intraday) and intermediate precision (interday) of rPN, expressed as a RSD\% of a series of measurements. The results are demonstrated in Table 1.

Statistical evaluation of the precision results showed that RSD\% values both intraday and interday were below $2 \%$. These results indicate that method precision is analytically acceptable [28].

The linearity of the method was examined in the range of $0.23-28.79 \mu \mathrm{g} / \mathrm{mL}$ and the calibration plots were chosen in this range. The statistical data evaluated by using rPN were presented in Table 2.

Good correlation fit the equation as $y=52511 x-0.0027$ with correlation coefficient of 0.9999 .

Accuracy was tested in both PIR and matrix solutions. The percentage error was calculated by use of the formula [(found concentration - spiked concentration)/spiked concentration] $\times 100 \%$. Results are shown in Table 3 .

The acceptance criteria are not higher than $2 \%$ deviation from the nominal value for accuracy [28]. The percent recoveries were found almost $100 \%$ for drug substance and drug product, and accuracy was much less than the acceptable criteria. Therefore, the accuracy results are highly satisfactory for the determination of PIR.

LOD and LOQ were estimated as [(standard deviation of regression equation)/(slope of the regression equation)] by multiplying with 3.3 and 10, respectively. The LOD was $0.07 \mu \mathrm{g} / \mathrm{mL}$ and the LOQ was $0.19 \mu \mathrm{g} / \mathrm{mL}$.

Specificity was performed using tablet inactive ingredients to assure that these common tablet dosage form ingredients could interfere with the peaks of interest. The data indicated that these ingredients did not interfere with PIR and IS peaks indicating the specificity of this method as seen in Figures 2(b) and 2(c).

3.3. Application of the Method to Determination of PIR in Tablets. The method was applied to pharmaceutical tablets (Felden tablet) containing $20 \mathrm{mg}$ active material. Samples were prepared as described in the experimental section. The peaks of tablet samples carried the characteristics of standard PIR, and there was no interference originating from the matrix as seen in Figure 2(d). The values of RSD\% were below $2 \%$ and the percent recoveries were almost $100 \%$ as seen in Table 4. The content of a tablet is in the limits of USP-24 requirements [29]. 


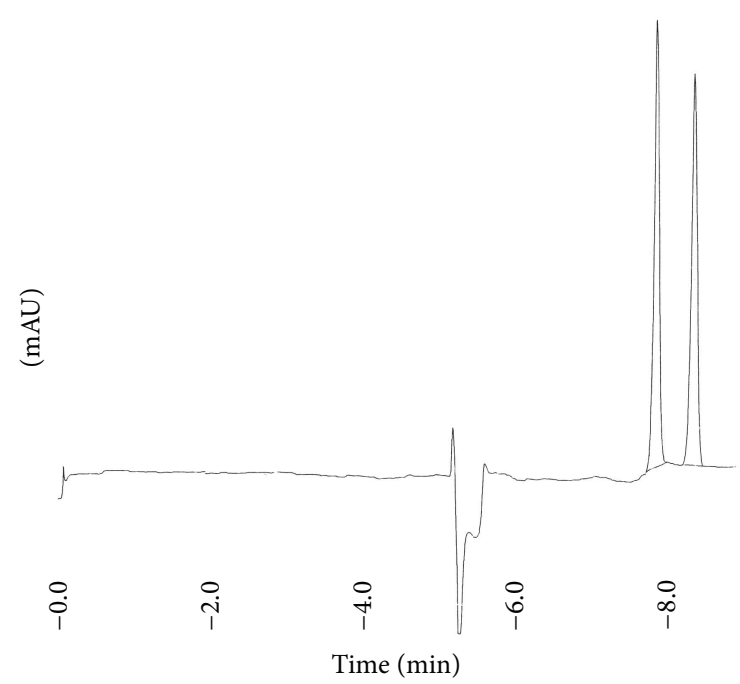

(a)

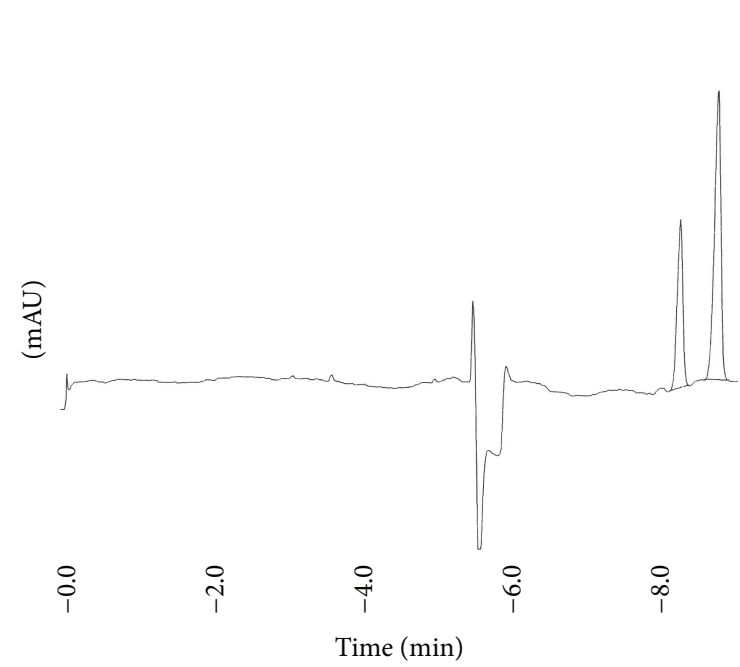

(c)

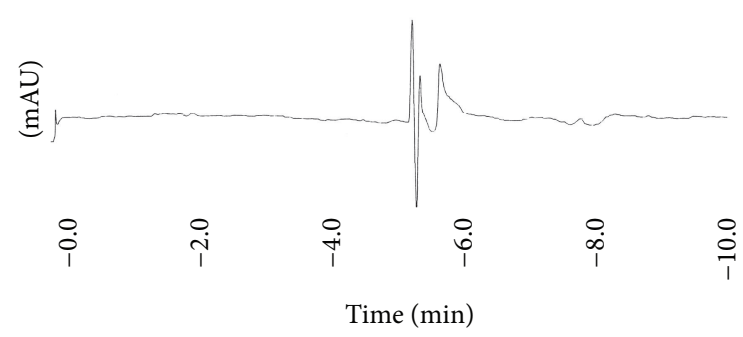

(b)

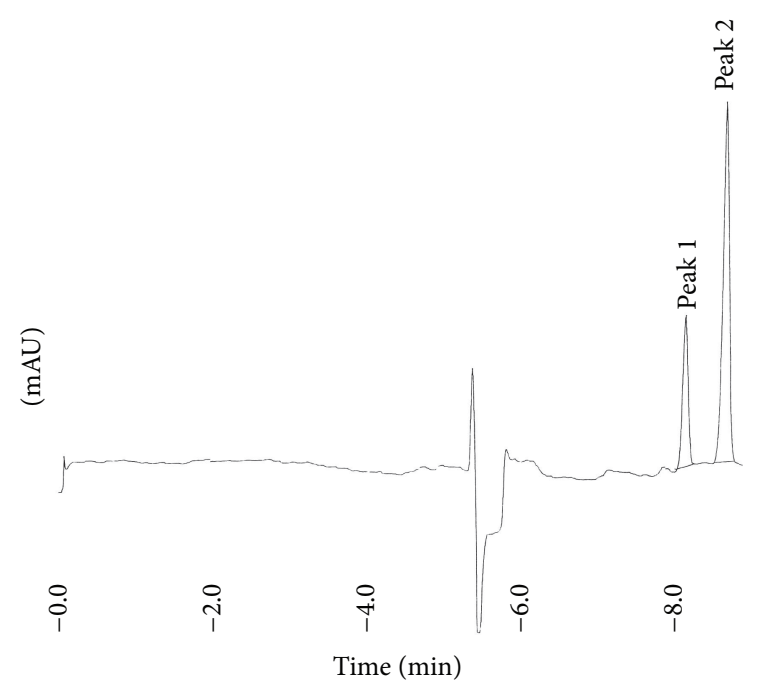

(d)

FIgURE 2: The electropherogram of (a) standard PIR $(7.20 \mu \mathrm{g} / \mathrm{mL})$ and IS $(6.76 \mu \mathrm{g} / \mathrm{mL})$, (b) matrix solution, (c) PIR spiked (2.58 $\mu \mathrm{g} / \mathrm{mL})$ matrix solution (IS $6.76 \mu \mathrm{g} / \mathrm{mL}$ ), and (d) tablet solution containing PIR $(2.58 \mu \mathrm{g} / \mathrm{mL}$ ) (IS $6.76 \mu \mathrm{g} / \mathrm{mL}$ ). Peak 1 is piroxicam (PIR); peak 2 is naproxen sodium (NAP) as internal standard (IS).

For the determination of PIR in commercial tablets, to compare the results of CZE method, UV spectrophotometric method was developed. The progressed CZE method was compared to a UV spectrophotometric method. The study was carried out at $204 \mathrm{~nm}$. Analysis was performed with standard addition method to show the selectivity parameter. A good linear relationship fitting the equation $[y=84691 x$ +0.3974 ], with high correlation coefficient (0.9999), was obtained between added amounts to tablet and absorbance values.

The UV spectrophotometric experimental values obtained for PIR are presented in Table 4. The results showed that UV spectrophotometric method was accurate and precise. And also the common tablet dosage form ingredients did not interfere with PIR peaks shown by standard addition technique, so the method was selective for PIR. UV spectrophotometry and CZE, used for the determination of PIR in tablets, were statistically compared with $t$ - and $F$ tests. They are demonstrated in Table 4.

The calculated $t$ value for the methods was 1.60 and was less than the table $t$ value (1.73) at 95\% confidence level. Calculated $F$ values were 0.77 and 2.14 for CZE and UV spectrophotometry, respectively. At $95 \%$ confidence level, the ratio of two $F$ values was calculated as 2.77 and was less than the table $F$ value (5.05). The difference between the two methods was found to be insignificant as a result of $t$ - and $F$ tests.

Although some of the chromatographic methods [14$20,22,23]$ seemed to have lower LODs and shorter analysis times, CZE methods need small amount of analyte volumes, and it takes shorter time to condition the capillary. This study has lower sensitivity than a previous chromatographic one [21]. Among the CE studies the sensitivity of this method either is better than in $[7,24,27]$ or could not be compared 
TABLE 1: Precision data for $1.79 \mu \mathrm{g} / \mathrm{mL}$ PIR.

\begin{tabular}{|c|c|c|c|c|}
\hline & \multicolumn{3}{|c|}{ Intraday } & \multirow{2}{*}{$\begin{array}{c}\text { Interdays } \\
\text { Whole days }(n=18)\end{array}$} \\
\hline & Day $1(n=6)$ & Day $2(n=6)$ & Day $3(n=6)$ & \\
\hline Mean & 0.284 & 0.286 & 0.286 & 0.285 \\
\hline $\mathrm{SD}$ & 0.004 & 0.004 & 0.004 & 0.005 \\
\hline $\mathrm{RSD} \%$ & 1.581 & 1.494 & 1.476 & 1.827 \\
\hline $\mathrm{CI}(P<0.05)$ & \pm 0.004 & \pm 0.003 & \pm 0.003 & \pm 0.002 \\
\hline
\end{tabular}

SD is standard deviation, RSD is relative standard deviation, CI is confidence interval, and $P<0.05$ is probability level of $95 \%$ for $n=6$ experiments (intraday) and for $n=18$ experiments (interdays).

TABLE 2: Calibration data for PIR.

\begin{tabular}{lcccc}
\hline & & Intraday & Interdays \\
& Day 1 $(n=6)$ & Day 2 $(n=6)$ & Day 3 $(n=6)$ & 51857 \\
\hline$a$ & 51518 & 52811 & 51240 & 0.003 \\
$b$ & 0.005 & -0.002 & 0.007 & 0.9998 \\
$R$ & 0.9999 & 0.9999 & 0.9999 & 0.059 \\
\pm Sr & 0.020 & 0.020 & 0.015 & 1.832 \\
$\mathrm{RSD} \%$ of $a$ & 1.089 & 1.070 & 0.857 & \pm 394 \\
$\mathrm{CI}(P<0.05)$ & \pm 463 & \pm 466 & \pm 362 & \\
\hline
\end{tabular}

$a$ is slope, $b$ is intercept, $R$ is correlation coefficient, Sr is standard deviation of regression equation, RSD is relative standard deviation, CI is confidence interval, and $P<0.05$ is probability level of $95 \%$ for $n=6$ experiments (intraday) and for $n=18$ experiments (interdays).

TABLE 3: Accuracy data for PIR.

\begin{tabular}{|c|c|c|c|c|c|}
\hline \multirow{20}{*}{ Standard } & \multirow{5}{*}{ Day $1(n=3)$} & Added $(\mu \mathrm{g} / \mathrm{mL})$ & 0.23 & 1.79 & 14.41 \\
\hline & & Found $($ mean $\pm S D)$ & $0.23 \pm 0.003$ & $1.8 \pm 0.02$ & $14.54 \pm 0.11$ \\
\hline & & Recovery\% & 102.61 & 100.26 & 101.15 \\
\hline & & SE\% & 2.61 & 0.26 & 1.15 \\
\hline & & RSD\% & 1.44 & 1.12 & 0.76 \\
\hline & \multirow{6}{*}{ Day $2(n=3)$} & Added $(\mu \mathrm{g} / \mathrm{mL})$ & 0.23 & 1.79 & 14.41 \\
\hline & & Found & $0.23 \pm 0.003$ & $1.79 \pm 0.002$ & $14.51 \pm 0.06$ \\
\hline & & Recovery\% & 99.95 & 99.76 & 100.78 \\
\hline & & $\mathrm{SE} \%$ & -0.05 & -0.23 & 0.78 \\
\hline & & RSD\% & 1.49 & 1.12 & 0.41 \\
\hline & & Added $(\mu \mathrm{g} / \mathrm{mL})$ & 0.23 & 1.79 & 14.41 \\
\hline & \multirow{4}{*}{ Day $3(n=3)$} & Found & $0.23 \pm 0.001$ & $1.8 \pm 0.01$ & $14.61 \pm 0.1$ \\
\hline & & Recovery\% & 102.45 & 100.47 & 101.61 \\
\hline & & $\mathrm{SE} \%$ & 2.45 & 0.47 & 1.61 \\
\hline & & RSD\% & 0.68 & 0.63 & 0.81 \\
\hline & \multirow{5}{*}{ Whole days $(n=9)$} & Added $(\mu \mathrm{g} / \mathrm{mL})$ & 0.23 & 1.79 & 14.41 \\
\hline & & Found & $0.23 \pm 0.003$ & $1.8 \pm 0.01$ & $14.54 \pm 0.1$ \\
\hline & & Recovery\% & 101.67 & 100.16 & 101.18 \\
\hline & & $\mathrm{SE} \%$ & 1.67 & 0.16 & 1.18 \\
\hline & & RSD\% & 1.67 & 0.72 & 0.69 \\
\hline \multirow{5}{*}{ Matrix } & \multirow{5}{*}{$(n=3)$} & Added $(\mu \mathrm{g} / \mathrm{mL})$ & 0.26 & 2.56 & 25.58 \\
\hline & & Found & $0.25 \pm 0.03$ & $2.56 \pm 0.01$ & $25.8 \pm 0.1$ \\
\hline & & Recovery\% & 99.76 & 100.21 & 100.94 \\
\hline & & SE\% & -0.24 & 0.21 & 0.94 \\
\hline & & RSD\% & 1.26 & 0.64 & 0.65 \\
\hline
\end{tabular}

$\mathrm{SD}$ is standard deviation, $\mathrm{SE}$ is standard error, and RSD is relative standard deviation for $n=3$ experiments (standard and matrix) and for $n=9$ experiments (standard, whole days). 
TABLE 4: Application and comparison of the methods.

\begin{tabular}{|c|c|c|c|c|c|c|c|}
\hline \multirow[b]{2}{*}{ Added PIR $(\mu \mathrm{g} / \mathrm{mL})$} & \multicolumn{3}{|c|}{$\mathrm{CE}(n=3)$} & \multicolumn{4}{|c|}{ UV spectrophotometry $(n=5)$} \\
\hline & 0.26 & 2.58 & 25.8 & 0.36 & 0.72 & 1.08 & 1.44 \\
\hline Recovery\% & 101.78 & 102.62 & 102.72 & 101.74 & 99.88 & 100.43 & 101.10 \\
\hline $\mathrm{SD}$ & 1.185 & 0.847 & 0.395 & 1.78 & 1.57 & 0.94 & 1.11 \\
\hline RSD \% & 1.165 & 0.826 & 0.385 & 1.75 & 1.57 & 0.94 & 1.10 \\
\hline $\mathrm{CI}^{*}$ & \pm 1.99 & \pm 1.43 & \pm 0.66 & \pm 1.69 & \pm 1.49 & \pm 0.89 & \pm 1.06 \\
\hline$T_{\text {calculated }}^{*}$ & & & & 1.60 & & & \\
\hline$T_{\text {table }}^{*}$ & & & & 1.73 & & & \\
\hline$F_{\text {calculated }}^{*}$ & & & & 2.77 & & & \\
\hline$F_{\text {table }}^{*}$ & & & & 5.05 & & & \\
\hline
\end{tabular}

CE is capillary electrophoresis, UV is ultraviolet, PIR is piroxicam, SD is standard deviation, RSD is relative standard deviation, CI is confidence interval, $*$ is probability level of $95 \%, t$ is Student's $t$-test, and $F$ is $F$-test for $n=3$ (CE) and for $n=5$ (UV) experiments.

because the sensitivity is not declared $[13,25,26]$. Some of the CE studies $[13,26,27]$ have shorter analysis time than this study. But also the developed method here has shorter analysis time with better resolution than a CE study [24] and could not be compared with some of them $[7,25]$ because the analysis time is not declared.

According to the best of our knowledge, the specificity of the proposed method was not shown in the tablet matrix in previous $\mathrm{CE}$ studies and the method sensitivity is the best one. Therefore, it could be a promising method for the possible application of PIR in biological matrix because of low detection limit.

\section{Conclusion}

In this study, a simple and rapid capillary electrophoretic method for the determination of PIR in tablets was developed and validated. Validation of the method has been shown with parameters of linearity, precision, LOD and LOQ, accuracy, and specificity. It was found that all the results of percent coefficient of variation are below $2 \%$ showing the method was valid. The CZE method developed here is proposed for the routine analysis of PIR in pharmaceutical formulations.

\section{Conflict of Interests}

The authors declare that there is no conflict of interests regarding the publication of this paper.

\section{References}

[1] M. Starek and J. Krzek, "A review of analytical techniques for determination of oxicams, nimesulide and nabumetone," Talanta, vol. 77, no. 3, pp. 925-942, 2009.

[2] A. Macià, F. Borrull, M. Calull, and C. Aguilar, "Capillary electrophoresis for the analysis of non-steroidal anti-inflammatory drugs," TrAC-Trends in Analytical Chemistry, vol. 26, no. 2, pp. 133-153, 2007.

[3] A. S. Amin, "Spectrophotometric determination of piroxicam and tenoxicam in pharmaceutical formulations using alizarin," Journal of Pharmaceutical and Biomedical Analysis, vol. 29, no. 4, pp. 729-736, 2002.
[4] A. S. Amin, H. A. Dessouki, and K. M. Khalil, "Indirect spectrophotometric determination of piroxicam and tenoxicam through oxidation with potassium permanganate," Bulletin of the Chemical Society of Ethiopia, vol. 24, no. 1, pp. 121-126, 2010.

[5] A. Klopas, I. Panderi, and M. Parissi-Poulou, "Determination of piroxicam and its major metabolite 5-hydroxypiroxicam in human plasma by zero-crossing first-derivative spectrophotometry," Journal of Pharmaceutical and Biomedical Analysis, vol. 17, no. 3, pp. 515-524, 1998.

[6] B. S. Nagaralli, J. Seetharamappa, and M. B. Melwanki, "Sensitive spectrophotometric methods for the determination of amoxycillin, ciprofloxacin and piroxicam in pure and pharmaceutical formulations," Journal of Pharmaceutical and Biomedical Analysis, vol. 29, no. 5, pp. 859-864, 2002.

[7] A. J. Nepote, L. Vera-Candiotti, M. R. Williner, P. C. Damiani, and A. C. Olivieri, "Development and validation of chemometrics-assisted spectrophotometry and micellar electrokinetic chromatography for the determination of fourcomponent pharmaceuticals," Analytica Chimica Acta, vol. 489, no. 1, pp. 77-84, 2003.

[8] M. I. Pascual-Reguera, M. J. Ayora-Canada, and M. S. Castro Ruiz, "Determination of piroxicam by solid-phase spectrophotometry in a continuous flow system," European Journal of Pharmaceutical Sciences, vol. 15, no. 2, pp. 179-183, 2002.

[9] H. Basan, N. G. Göger, N. Ertaş, and M. T. Orbey, "Quantitative determination of piroxicam in a new formulation (piroxicam$\beta$-cyclodextrin) by derivative UV spectrophotometric method and HPLC," Journal of Pharmaceutical and Biomedical Analysis, vol. 26, no. 2, pp. 171-178, 2001.

[10] J. A. Arancibia and G. M. Escandar, "Two different strategies for the fluorimetric determination of piroxicam in serum," Talanta, vol. 60, no. 6, pp. 1113-1121, 2003.

[11] G. M. Escandar, A. J. Bystol, and A. D. Campiglia, "Spectrofluorimetric method for the determination of piroxicam and pyridoxine," Analytica Chimica Acta, vol. 466, no. 2, pp. 275283, 2002.

[12] K. C. Ramesh, B. G. Gowda, J. Seetharamappa, and J. Keshavayya, "Indirect spectrofluorimetric determination of piroxicam and propranolol hydrochloride in bulk and pharmaceutical preparations," Journal of Analytical Chemistry, vol. 58, no. 10, pp. 933-936, 2003.

[13] H. Bartsch, A. Eiper, and H. Kopelent-Frank, "Stability indicating assays for the determination of piroxicam-comparison of methods," Journal of Pharmaceutical and Biomedical Analysis, vol. 20, no. 3, pp. 531-541, 1999. 
[14] A. Crecelius, M. R. Clench, D. S. Richards, and V. Parr, "Quantitative determination of piroxicam by TLC-MALDI TOF MS," Journal of Pharmaceutical and Biomedical Analysis, vol. 35, no. 1, pp. 31-39, 2004.

[15] M. Amanlou and A. R. Dehpour, "Rapid method for the determination of piroxicam in rat plasma using high-performance liquid chromatography," Journal of Chromatography B, vol. 696, no. 2, pp. 317-319, 1997.

[16] A. D. de Jager, H. Ellis, H. K. L. Hundt, K. J. Swart, and A. F. Hundt, "High-performance liquid chromatographic determination with amperometric detection of piroxicam in human plasma and tissues," Journal of Chromatography B: Biomedical Sciences and Applications, vol. 729, no. 1-2, pp. 183-189, 1999.

[17] M. Yritia, P. Parra, J. M. Fernández, and J. M. Barbanoj, "Piroxicam quantitation in human plasma by high-performance liquid chromatography with on- and off-line solid-phase extraction," Journal of Chromatography A, vol. 846, no. 1-2, pp. 199-205, 1999.

[18] H. Y. Ji, H. W. Lee, Y. H. Kim, D. W. Jeong, and H. S. Lee, "Simultaneous determination of piroxicam, meloxicam and tenoxicam in human plasma by liquid chromatography with tandem mass spectrometry," Journal of Chromatography B: Analytical Technologies in the Biomedical and Life Sciences, vol. 826, no. 1-2, pp. 214-219, 2005.

[19] S. Dadashzadeh, A. M. Vali, and N. Rezagholi, "LC determination of piroxicam in human plasma," Journal of Pharmaceutical and Biomedical Analysis, vol. 28, no. 6, pp. 1201-1204, 2002.

[20] A. Doliwa, S. Santoyo, M. A. Campanero, and P. Ygartua, "Sensitive LC determination of piroxicam after in vitro transdermal permeation studies," Journal of Pharmaceutical and Biomedical Analysis, vol. 26, no. 4, pp. 531-537, 2001.

[21] X.-Y. Song, Y.-P. Shi, and J. Chen, "A novel extraction technique based on carbon nanotubes reinforced hollow fiber solid/liquid microextraction for the measurement of piroxicam and diclofenac combined with high performance liquid chromatography," Talanta, vol. 100, pp. 153-161, 2012.

[22] J. Shirako, M. Kawasaki, K. Komine et al., "Simultaneous determination for oxicam non-steroidal anti-inflammatory drugs in human serum by liquid chromatography-tandem mass spectrometry," Forensic Science International, vol. 227, no. 1-3, pp. 100-102, 2013.

[23] G. Dowling and E. Malone, "Analytical strategy for the confirmatory analysis of the non-steroidal anti-inflammatory drugs firocoxib, propyphenazone, ramifenazone and piroxicam in bovine plasma by liquid chromatography tandem mass spectrometry," Journal of Pharmaceutical and Biomedical Analysis, vol. 56, no. 2, pp. 359-365, 2011.

[24] Y.-L. Chen and S.-M. Wu, "Capillary zone electrophoresis for simultaneous determination of seven nonsteroidal antiinflammatory drugs in pharmaceuticals," Analytical and Bioanalytical Chemistry, vol. 381, no. 4, pp. 907-912, 2005.

[25] C. M. Boone, J. W. Douma, J. P. Franke, R. A. De Zeeuw, and K. Ensing, "Screening for the presence of drugs in serum and urine using different separation modes of capillary electrophoresis," Forensic Science International, vol. 121, no. 1-2, pp. 89-96, 2001.

[26] M. Fillet, I. Bechet, V. Piette, and J. Crommen, "Separation of nonsteroidal anti-inflammatory drugs by capillary electrophoresis using nonaqueous electrolytes," Electrophoresis, vol. 20, pp. 1907-1915, 1999.

[27] M. G. Donato, W. Baeyens, W. Van Den Bossche, and P. Sandra, "The determination of non-steroidal antiinflammatory drugs in pharmaceuticals by capillary zone electrophoresis and micellar electrokinetic capillary chromatography," Journal of Pharmaceutical and Biomedical Analysis, vol. 12, no. 1, pp. 2126, 1994.

[28] “ICH, Q2(R1), Harmonized Tripartite Guideline, Validation of Analytical Procedures: Text and Methodology," in International Conference on Harmonization of Technical Requirements for Registration of Pharmaceuticals for Human Use, 2005.

[29] United States Pharmacopoeia/National Formulary, Pharmacopeial Convention, Rockville, Md, USA, 24th edition, 2000. 

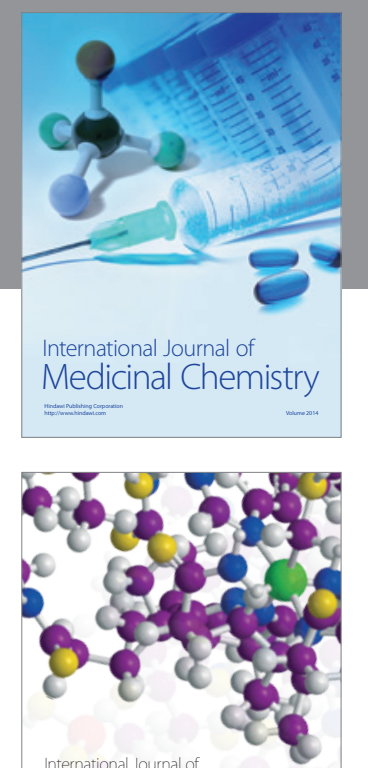

\section{Carbohydrate} Chemistry

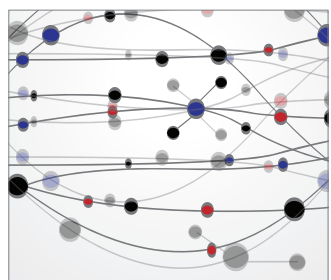

The Scientific World Journal
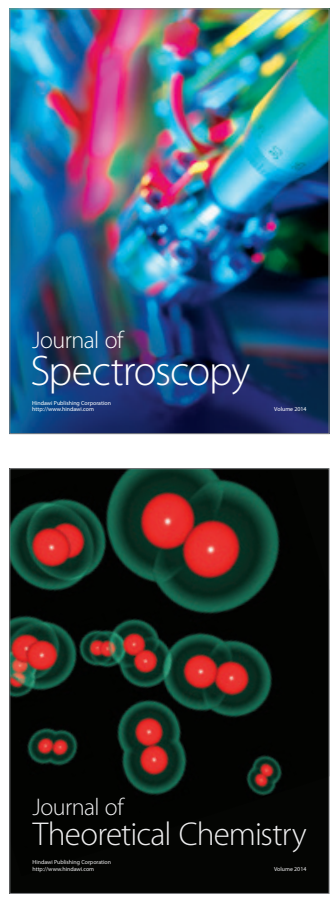
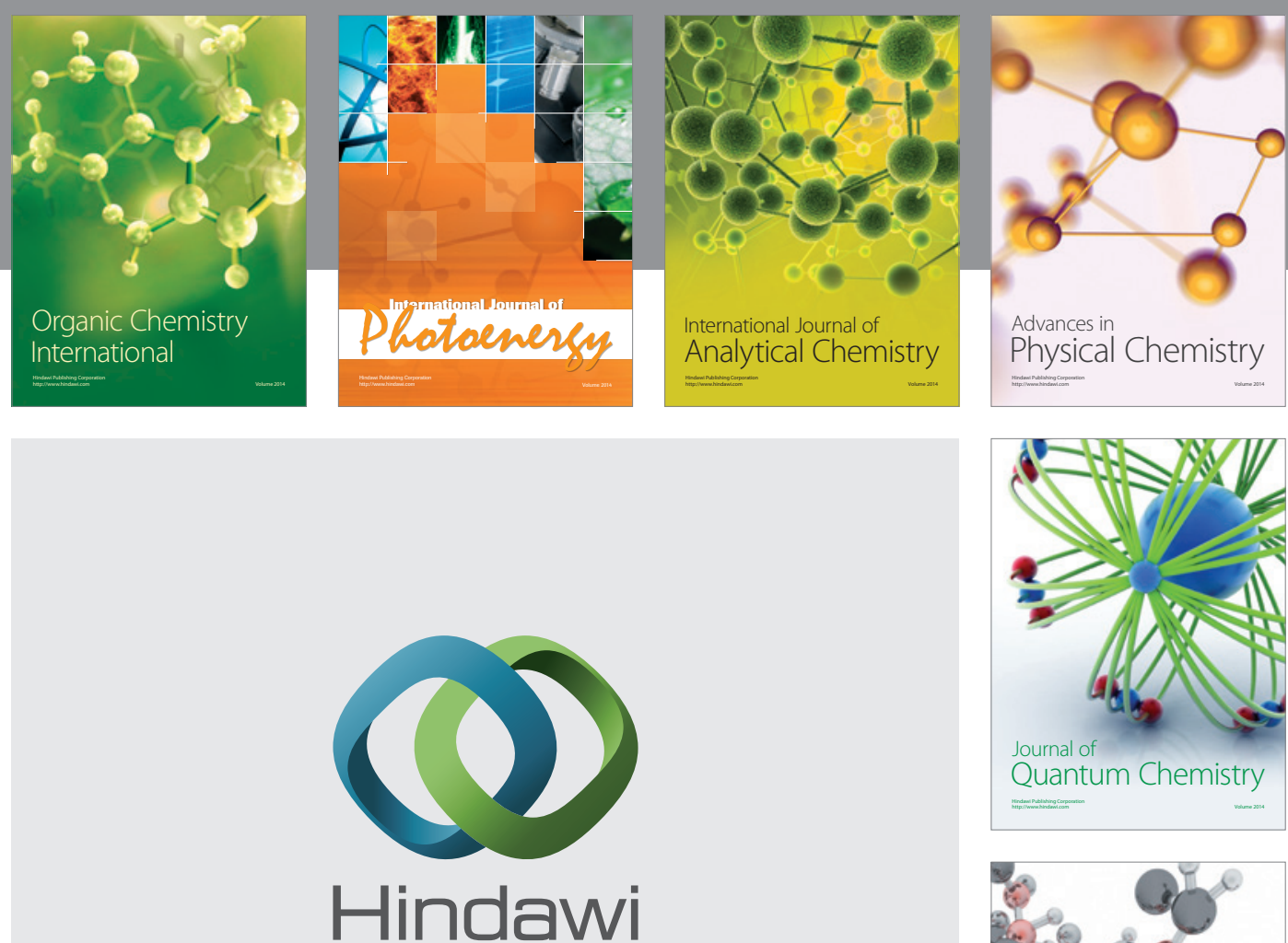

Submit your manuscripts at

http://www.hindawi.com

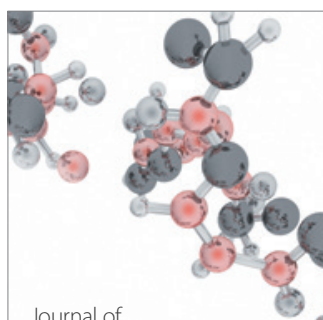

Analytical Methods

in Chemistry

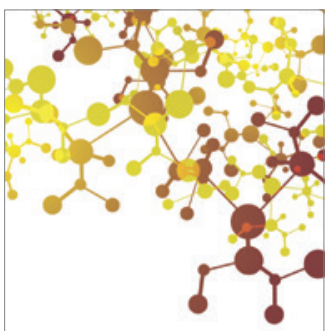

Journal of

Applied Chemistry

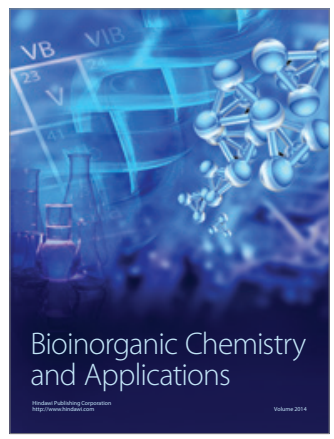

Inorganic Chemistry
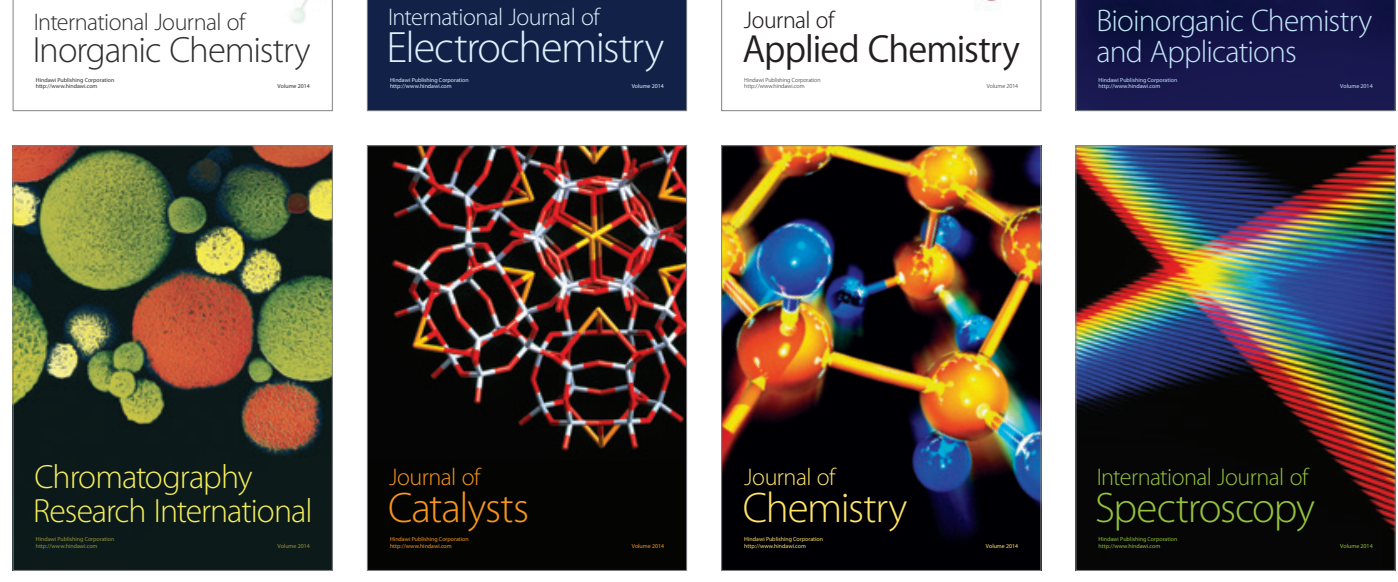